\title{
O DRAMA EXISTENCIAL DE BRÁS CUBAS: aproximações filosóficas em Memórias Póstumas de Brás Cubas, O Discurso de Metafísica de Leibniz e $O$ Cândido de Voltaire
}

\section{THE EXISTENTIAL DRAMA OF BRÁS CUBAS: philosophical approaches in Posthumous Memoirs of Brás Cubas, Leibniz's Discourse on Metaphysics and Voltaire's Cândido}

Eleno Marques de Araújo ${ }^{1 *}$, Maria Eduarda Martins Cruvinel ${ }^{1}$, Lara Mamede de Almeida ${ }^{1}$, Victor Rodrigues de Souza ${ }^{1}$

\begin{abstract}
RESUMO
O objetivo deste texto é demonstrar que nas três obras indicadas para análise há um elo entre filosofia e literatura. Aqui seguimos a metodologia da revisão bibliográfica. Em uma segunda abordagem pretendemos tratar mais especificamente do Humanitismo, a teoria filosófica de Quincas Borba. Por ora, nos ocuparemos de demonstrar que filosofia e literatura estão em entrelaçadas por retratar dimensões do conhecimento humano e que caracterizam uma linguagem de questionamento e exposição de pensamento de forma concreta. Ambas buscam aspectos sólidos de discussão de vários significados possíveis para questões humanísticas. Tal abordagem une as obras: Memórias póstumas de Brás Cubas de Machado de Assis, O Discurso de Metafísica de Leibniz e Cândido de Voltaire. Assis deixa transparecer em sua obra que conhecia as obras filosóficas de Leibniz e Voltaire. Quincas Borba, o fundador do Humanitismo, o princípio de todas as coisas, emanando de Humanistas. Ao morrer afirmava que a dor é uma ilusão, e os ensinamentos dados a Cândido, por Pangloss, tinham razão de ser. Pois apesar da dor e do sofrimento a realidade da vida sempre é a melhor de todas as situações. Com tal convicção Quincas aponta para uma conclusão: a certeza de Leibniz que "este é o melhor dos mundos possíveis".
\end{abstract}

Palavras-chave. Literatura. Filosofia. Existencialismo. Humanitismo.

\section{ABSTRACT}

\footnotetext{
1* Doutor em Ciências da Religião. Professor titular na UNIFIMES. Doutorando no programa de PósGraduação em Ciências da Educação no CIA/Univerdidad del Sol, em Asunción - Py. profelenoaraujo@outlook.com;. Discentes no curso de Medicina da UNIFIMES e bolsistas da pesquisa.
} 
The objective of this text is to demonstrate that in the three works indicated for analysis there is a link between philosophy and literature. Here we follow the methodology of the literature review. In a second approach, we intend to deal more specifically with Humanitism, Quincas Borba's philosophical theory. For now, we will take care to demonstrate that philosophy and literature are intertwined as they portray dimensions of human knowledge and that they characterize a language of questioning and exposition of thought in a concrete way. Both seek solid aspects of discussion of various possible meanings for humanistic questions. This approach unites the works: Posthumous Memoirs of Brás Cubas by Machado de Assis, The Discourse on Metaphysics by Leibniz and Cândido by Voltaire. Assisi shows in his work that he was familiar with the philosophical works of Leibniz and Voltaire. Quincas Borba, the founder of Humanitism, the principle of all things, emanating from Humanists. When he died, he claimed that pain is an illusion, and the teachings given to Candide, by Pangloss, were justified. Because despite the pain and suffering, the reality of life is always the best of all situations. With such conviction Quincas points to a conclusion: Leibniz's certainty that "this is the best of all possible worlds".

Keywords. Literature. Philosophy. Existentialism. Humanitism.

\section{INTRODUÇÃO}

Os entes parecem ter um ciclo dinâmico na natureza, mas uma observação atenta mostra que a physis é diferente. Deste observar curioso nasce a filosofia, isto é, vem à existência. Antes mesmo de começar a historiografia irrompeu nas antigas colônias gregas da Ásia menor, na Jônia, o que hoje conhecemos como filosofia. A Jônia era a zona periférica da Grécia Antiga e foi lá que o pensamento filosófico teve sua origem na plebe-grega. Foi das insatisfações humanas que o homem (Filósofo) perguntou pela existência ontológica: O que é? Isto é, pela existência do Ser.

Tales de Mileto foi o primeiro homem a indagar pela essência do ser, a partir de uma profunda observação da physis. Às pegadas de Tales, seguiram seus contemporâneos e sucessores os filósofos da natureza, ou como são mais conhecidos os Pré-Socráticos. Eles observaram que "pássaros banham em cinzas" e "porcos em lama", que do "uno a multiplicidade e da multiplicidade a unidade", que "o mesmo é pensar e, portanto, ser". Desde então muitos outros propuseram as mais variadas teorias ou os mais complexos sistemas filosóficos. Em uma classificação geral da história da filosofia percebemos os 
Pré-Socráticos, e entre eles os clássicos Sócrates, Platão e Aristóteles; os medievais; os modernos e os contemporâneos. Mais próximo a nós estão os filósofos existencialistas.

Os existencialistas, mais expecificamente, dedicaram suas vidas, seus trabalhos na investigação do Ser. Será possível afirmar que algo realmente existe? Em quais formas pode expressar este Ser? A conclusão dessa investigação culminou com o drástico drama da existência humana. Esvaziaram de tal forma a existência humana, que houve até quem decretou a morte de Deus. Tal realidade levou os próprios filósofos a um vazio interior. Entre eles, um pelo menos, até enlouqueceu. O vazio aqui tratado está relacionado á existência humana. Uma questão existencial no pleno sentido do termo passa pela ontologia, isto é, a pergunta do ser enquanto ser, ou seja, sua existência enquanto ser apriori. Um exemplo é Sartre: o filósofo do NADA e do SER, um poço de angustia humana.

Neste artigo propusemos analisar a questão da unidade entre Literatura e Filosofia, a partir da obra Memórias Póstumas de Brás Cubas. Nela, Assis apresenta, por meio de Quincas Borba, um complexo sistema filosófico denominado de Humanitismo. Defenderemos uma tese que Assis conhecia as obras O Discurso de Metafísica de Leibniz e $O$ Cândido de Voltaire. Assis faz referência ao doutor Pangloss, um personagem de Cândido, usado por Voltaire para ridicularizar Leibniz.

Assis descreve os dramas da existência humana no desenrolar da vida dos personagens Quincas Borba, o criador do Humanitismo, e do próprio Brás Cubas, com todas as suas idas e vindas. Uma leitura de Memórias Póstumas levará necessariamente à conclusão que entre a vida de Quincas Borba e a de Cândido há um elo muito grande. Ambos têm uma infância abastada. O primeiro estuda em escola particular e sempre é destaque em papéis representativos em peças teatrais e celebrações comemorativas, mas sempre como nobre e nunca como alguém da plebe. O segundo é aluno do preceptor Plangloss no castelo do barão de Thunder-ten-tronckh, considerado um paraíso terrestre. Porém, eles vão da nobreza à miséria. Padecem violências. Fome e roubo. Quincas morre semi-demente, a exemplo do filósofo existencialista - Friedrich Nietsche. Cândido ao final da obra está muito pobre e tem de trabalhar para sua própria subsistência, com um clássico convite que Voltaire (1997, p. 94) faz: “mas devemos cultivar nosso jardim”. Passemos, portanto, a análise das obras individualmente. 
A relação existente entre eles se dá na questão da formação pessoal, isto é, no processo escolar. Embora os textos não falam da condição econômica dos dois, ambos têm acesso ao saber. Mesmo com tanto estudo e boa formação ambos vão ao vazio profundo, seria para conhecer sua própria existência humana? Ou será, que todos os que perguntaram sobre a existência humana caíram numa na loucura ou no desequilíbrio?

\section{A FILOSOFIA DE QUINCAS BORBA}

Assis (1997, p. 15), por meio do personagem Brás Cubas, deixa o leitor um tanto quanto meditativo com a dedicatória que faz. "Ao verme que primeiro roeu as frias carnes do meu cadáver Dedico como saudosa lembrança estas memórias póstumas”. O caráter filosófico já transparece logo no início da obra com esta dedicação e levanta algumas interrogações: Qual o sentido de dedicar uma obra a um verme? Qual a predileção ao primeiro? Haverá aqui uma referência ao Darwinismo social da luta pela própria sobrevivência? O verme que primeiro rói é o mais forte e o vencedor?

A orientação ao leitor vem logo em seguida, porém quanto à preferência do mesmo em relação ao texto a ser lido. "Creio que prefere a anedota à reflexão, como os outros leitores, seus confrades, e acho que faz muito bem. Pois lá iremos. Todavia, importa dizer que este livro é escrito com pachorra, com a pachorra de um homem já desafrontado da brevidade do século [...]" (ASSIS, 1997, p. 22). Contudo a obra deve ser lida com um olhar filosófico, pois ela é "obra supinamente filosófica, de uma filosofia desigual, agora austera, logo brincalhona, coisa que não edifica nem destrói, não inflama nem regela, e é todavia mais do que passatempo e menos do que apostado" (ASSIS, 1997, p. 22). No desenrolar do o texto aparece uma interrogação sobre os dramas da existência humana, como por exemplo, na seguinte passagem onde é abordada a questão da sina ou da predestinação. "Por que... não sei por que... porque é a minha sina..." (ASSIS, 1997, p. 44). O que é a sina? Existe uma predestinação? O contexto da reflexão é um adultério. As paixões e as consequências daí decorrentes. Mas, assumir isso como sina, como predestinação parece ser simplista demasiadamente. Antes de aprofundar nos desdobramentos da vida de Brás Cubas o autor apresenta a intenção do livro, a preocupação está em relação às intenções do leitor ao saber do propósito de tal obra: "não sei se digo; este livro é casto, ao menos na intenção; na intenção é casticismo. Mas vá lá; 
ou se há de dizer tudo ou nada" (ASSIS, 1997, p. 47). Dadas estas informações iniciais o autor passa a descrever as idas e vinda de Cubas. Primeiro vem às aventuras do amor.

Primeira comoção da minha juventude, que doce que me foste! Tal devia ser, na criação bíblica, o efeito do primeiro sol. Imagina tu esse efeito do primeiro sol, a bater de chapa na face de um mundo em flor. Pois foi a mesma coisa, leitor amigo, e se alguma vez cantaste dezoito anos, deves lembrar-te que, foi assim mesmo (ASSIS, 1997, p. 49).

Como na vida nem tudo é só alegria e nem sempre as recordações são as melhores, percebemos que o narrador pretende mostrar exatamente que esta realidade vai se revezando e logo vêm às dificuldades: "pagava-me à tanta os sacrifícios; espreitava os meus mais recônditos pensamentos. Não havia desejo a que não acudisse com calma, sem esforço, por uma espécie de lei da consciência e necessidade do coração. Nunca o desejo era razoável, mas um capricho puro [...]" (ASSIS, 1997, p. 52). Assis descreve o namoro de Brás com Marcela de uma forma quase que comercial, abordando inclusive valores econômicos: "Marcela amou-me durante quinze meses e onze contos de reis; nada menos" (ASSIS, 1997, p. 53). O valor de onze contos de reis fora gastos com presentes que dava à moça, mesmo que para isso, deixasse seu pai em dificuldades financeiras.

Com a decisão do pai de Brás em mandá-lo a Europa para estudar, com a finalidade de separá-lo de Marcela, com quem estava namorando e gastava muito com os presentes dados à moça. Em função de seu pai forçá-lo a ir a Europa Brás está frente a realidade 'nua e crua' de uma pessoa desesperada. Vive o sentimento de perca e que quase sempre leva a um vazio existencial profundo:

Saí desatinado; gastei duas mortais horas em vaguear pelos bairros mais excêntricos e desertos, onde fosse difícil dar comigo. Ia mastigando o meu desespero, com uma espécie de gula mórbida: evocava os dias, as horas, os instantes de delírio, e ora me comprazia em crer que eles eram eternos, que tudo aquilo era um pesadelo, ora, enganando-me a mim mesmo, tentava rejeitá-los de mim, como um fardo inútil. Então resolvia embarcar imediatamente para cortar a minha vida em duas metades, e deleitava-me com a idéia de que Marcela, sabendo da partida, ficaria ralada de saudade e remorsos (ASSIS, 1997, p. 54).

O navio com os seus tripulantes representam, de certa forma, a existência humana, entre os passageiros estão pessoas felizes indo passear; pessoa que por seu estado 
débil inclusive vem a óbito durante a viagem; passageiro em profundo estado de loucura. "[...] um homem doido, acompanhado pela mulher, dois rapazes que iam a passeio, quatro comerciantes e dois criados. [...] O capitão do navio, que, aliás, tinha muito que cuidar de si, porque, além do mais, levava a mulher tísica em último grau” (Assis, 1997, p. 57). Mais tarde ele descreve a morte da mulher do capitão. "Pobre Leocádia! Murmurou sem responder ao pedido. Um cadáver... o mar... o céu... o navio...” (ASSIS, 1997, p. 61). O velório se deu no navio e o mar abriu suas águas, como que uma grande sepultura, para receber o corpo de Leocádia.

Assim que chegou a Portugal teve um incidente com um burro que montara. Caindo do animal ficou preso a ele, pois seu pé não saiu do estribo, correndo um grande risco de ser arrastado ou pisoteado pelo animal. Salvo graças a ação corajosa de um escravo ele decide dar três moedas de ouro como recompensa, mas se arrepende imediatamente. "Resolvi dar-lhe três moedas de ouro das cinco que trazia comigo; não porque era uma recompensa digna da dedicação com que ele me salvou. Está dito, doulhe as três moedas" (ASSIS, 1997, p. 63). Imediatamente ter dado as três moedas batelhe um arrependimento profundo e chega facilmente à conclusão de que devia ter dado só uma, pois o esforço do almocreve não tinha sido grande e depois não aconteceu nada, isto é, sensação de dinheiro jogado fora. E depois o próprio almocreve diz: "Se o jumento corre por aí afora, é possível; mas, com a ajuda do cavalo, viu vós mecê que não aconteceu nada (ASSIS, 1997, p. 64).

A estada de Cubas em Portugal não rendeu o que o seu pai esperava, mas diante da enfermidade de sua esposa suplica ao filho que volte. "Ao cabo de alguns anos de peregrinações, atendi às súplicas de meu pai: 'Vem, dizia ele na última carta; se não vieres depressa, acharás tua mãe morta!' (ASSIS, 1997, p. 65). Cubas continua descrevendo seu drama e recorda o momento de sua partida do Brasil:

Esta última palavra foi para mim um golpe. Eu amava minha mãe; tinha ainda diante dos olhos as circunstâncias da última bênção que ela me dera, a bordo do navio. 'Meu triste filho, nunca mais te verei', soluçava a pobre senhora apertando-me ao peito. E essas palavras ressoavam-me agora, como uma profecia realizada (ASSIS, 1997, p. 65). 
A viagem de retorno não poderia ter sido diferente. Sua mente só ocupara de pensamentos doloridos, pois tinha uma grande dúvida se acharia sua mãe viva. A descrição que seu pai fizera o colocou diante da morte da pessoa amada "eu amava minha mãe". Como encarar a dor da perca?

\begin{abstract}
Longa foi a agonia, longa e cruel, de uma crueldade minuciosa, fria, repisada, que me encheu de dor e estupefação. Era a primeira vez que eu via morrer alguém. Conhecia a morte de oitiva; quando muito, tinha-a visto já petrificada no rosto de algum cadáver, que acompanhei ao cemitério, ou traz-lhe a ideia embrulhada nas amplificações de retórica dos professores de coisas antigas, a morte aleivosa de César, a austera de Sócrates, a orgulhosa de Catão. Mas esse duelo do ser e do não ser, a morte em ação, dolorida, contraída convulsa, sem aparelho político ou filosófico, a morte de uma pessoa amada, essa foi a primeira vez que a pude encarar (ASSIS, 1997, p. 67).
\end{abstract}

A morte da mãe de Cubas levou-o a um estado depressivo, comum em circunstâncias de morte. $\mathrm{O}$ autor da obra quis mostrar a fragilidade do ser humano neste momento de separação, de perca, de dor. A reação foi a mesma de todas as pessoas. Uma tentativa de fugir do mundo, do confronto com outras pessoas e isolar-se no silêncio e na solidão:

[...] Com efeito, ao cabo de sete dias, estava farto da solidão; a dor aplacara; o espírito já se não contentava com o uso da espingarda e dois livros, nem com a vista do arvoredo e do céu. Reagia à mocidade, era preciso viver. Meti no baú o problema da vida e da morte, os hipocondríacos do poeta, as camisas, as meditações, as gravatas, e ia fechá-lo [...] (ASSIS, 1997, p. 70).

Vendo a dor e o sofrimento de Cubas seu pai vai ao seu encontro “[...] Olá, meu rapaz, isto não é vida!” (ASSIS, 1997, p. 71). Certamente a dor do pai ao ver a dor do filho o move para ajudá-lo a sair daquele estado depressivo. A visita não era a toa tinha um propósito. O filho devia sair do estado depressivo. Depois de confortá-lo dizendo que a vontade de Deus devia ser aceita, uma espécie de predestinação, faz-lhe duas propostas.

A primeira era casar-se com Eugênia. A segunda de fazer careira política. Inicialmente recusou as duas propostas, mas, depois aceitou visitar a moça. "Apertei-lhes a mão e saí, a rir comigo da superstição das duas mulheres, um rir filosófico, desinteressado, superior" (ASSIS, 1997, p. 79). 
Ainda naquela casa retirada Brás recebe a misteriosa visita de uma borboleta preta o que lhe causa estranheza e levanta uma serie de interrogações. O que tem a ver a borboleta e ele? Porque a borboleta devia ser azul e não preta como era? Seria uma questão de racismo? Seria discriminação, como reflexo de sua própria cor? "Era negra como a noite. [...] Tinha um certo ar escarninho que me aborreceu muito. Dei de ombros, sai do quarto; mas tornando lá, minutos depois, achando-a ainda no mesmo lugar, senti um repelão dos nervos, lancei mão de uma toalha, bati-lhe e ela caiu" (ASSIS, 1997, p. 79). Porque esta borboleta preta mexeu tanto com os sentimentos de Cubas? Ele continua descrevendo a sena com certa preocupação:

Passa pela minha janela entra e dá comigo. Suponho que nunca teria visto um homem; não sabia, portanto, o que era o homem; descreveu infinitas voltas em torno do meu corpo, e viu que me movia, que tinha olhos, braços, pernas, um ar divino, uma estrutura colossal. Então disse consigo: 'Este é provavelmente o inventor das borboletas' (ASSIS, 1997, p. 80).

A elucubração de Brás com a manifestação da borboleta leva-o a repensar sua própria existência e o faz pensar em Virgília. No passado houve uma proposta de casamento entre Brás Cubas e Virgília que não se concretizou. Ela decidiu casar-se com Lobo Neves. Mas certamente amavas a Cubas e o casamento não lhe traria a felicidade. "Lá dentro ela poderia, e não pouco - ou fosse mágoa pura, ou só despeito; e porque a dor que se dissimula dói mais, é mui provável que Virgília padecesse em dobro do que realmente devia padecer. Creio que isto é metafísica" (ASSIS, 1997, p. 94).

O caso sexual extra conjugal que inicia entre ele é descrito de forma contagiante. “Outra coisa que também me parece metafísica é isto: dá-se movimento a uma bola, por exemplo; rola esta, encontra outras bolas, transmite-lhes o impulso, e eis a segunda bola a rolar como a primeira rolou" (ASSIS, 1997, p. 94). No fundo o que ele quer dizer é que percebeu os sentimentos de Virgília e deixou ser contagiado por eles. O impulso vindo de Virgília (primeira bola) atinge a ele (segunda bola) e ambos estão rolando, os sentimentos de antes ainda não acabaram.

A morte do pai de Brás fez com que a família se dividisse em função dos bens materiais a serem herdados por ele e sua irmã. "Fizeram-se finalmente as partilhas, mas nós estávamos brigados. E digo-lhes que, ainda assim, custou-me muito brigar com 
Sabina. Éramos tão amigos!” (ASSIS, 1997, p. 100). No entanto, ele continua a lamentar a separação ou a briga com a irmã. "Jogos pueris, fúrias de criança, risos e tristezas da idade adulta, dividimos muitas vezes esse pão da alegria e miséria, irmãmente, como bons irmãos que éramos. Mas estávamos brigados. Tal qual a beleza de Marcela, que se esvaiu com as bexigas (ASSIS, 1997, p. 100).

No lamento de Cubas fica evidente que apesar da separação, da dor e do sofrimento em função da morte do pai, o que fala mais alto é o dinheiro, a posse, os bens matérias em detrimento das relações humanas ou fraternas. A morte do pai levou Brás novamente a um estado depressivo. "Vivi meu recluso, indo de longe em longe a algum baile, ao teatro, ou palestra, mas, a maior parte do tempo passei-a comigo mesmo. Vivia, deixava-me ir ao curso e recurso dos sucessos e dos dias, ora buliçoso, ora apático, entre a ambição e o desânimo" (ASSIS, 1997, p. 101).

$\mathrm{O}$ apego aos bens materiais continua sendo descrito a partir de dois objetos achados. O primeiro é uma moeda que Cubas encontrou na rua. Passa-lhes vários questionamentos à mente. Finalmente ele a devolve assim como que para ninguém pois, como alguém poderia provar que aquele objeto lhe pertencia? Brás Cubas envia-a ao delegado de polícia acompanhada de uma carta pedindo-lhe que utilizasse dos meios disponíveis para restituí-la ao verdadeiro dono. É evidente que este acontecimento rendeu-lhes nobres elogios. Depois de tê-la enviado a moeda a polícia tira a seguinte conclusão: “eu, Brás Cubas, descobri uma lei sublime, a lei da equivalência das janelas, e estabeleci que o modo de compensar uma janela fechada é abrir outra, afim de que a moral possa arejar continuamente as consciências" (ASSIS, 1997, p. 106). Entretanto, o próprio Brás não chegaria ao verdadeiro proprietário da moeda, mas teria meios ao delegado de polícia para chegar?

O segundo objeto ele encontrou durante uma caminhada na praia, um pacote fechado. Dentro do embrulho continha cinco contos. Este valor era infinitamente superior à moeda devolvida. "Não se perdem cinco contos, como se perde um lenço de tabaco. Cinco contos levam-se com trinta mil sentidos, apalpam-se a miúdo, não se lhes tiram os olhos de cima, nem as mãos, nem o pensamento, e para se perderem assim totalmente em uma praia, é necessário que..." (ASSIS, 1997, p. 108). Este achado não criou-lhe nenhum tipo de constrangimento. "Crime é que não podia se achado; nem crime, nem desonras, nem nada que embaciasse o caráter de um homem" (ASSIS, 1997, p. 108). Ele tratou de 
guardá-lo como que se um objeto achado fosse automaticamente propriedade sua. Aqui devemos perceber a contradição na consciência de um homem, no caso Brás que não apropria de uma moeda e chega a ser exaltado pelo delegado, mas apropria de um valor muito superior ao não dar aos cinco contos o mesmo destino da moeda. O que muda na vida de uma pessoa que tem um drama com pouco valor, caso da moeda, e não causa nenhum remorso ao apossar dos cinco contos para si?

Pouco tempo depois, Brás usará os cinco contos para comprar a consciência da velha que emprestava a sua casa para ele manter os encontros amorosos com Virgília. Após os primeiros encontros a velha remoía de remorso em saber que sua casa estava sendo usada como ponto de encontro para a realização de um adultério. Logo que ela ganha os cinco contos sua consciência fica tranquila. Dinheiro que não era dele, não provocou nele nenhum gesto de constrangimento e ao afinal serviu para comprar uma consciência maculada. O que passa na mente humana quando uma simples moeda é causa de grandes perturbações por pertencer à outra pessoa, ao passo que cinco contos uma quantia significativa não lhe causa nenhuma perturbação? Ademais, o que passa na consciência da velha, que vivia o drama de sua casa ser local de adultério, mas que tudo fica normal ao receber os cinco contos?

Mergulhado no drama da existência humana, Brás faz uma reflexão sobre a finalidade do nariz, ou melhor, por que a pessoa tem nariz? "Nariz, consciência sem remorsos, tu me valeste muito na vida... já meditaste alguma vez no destino do nariz, amado leitor? (ASSIS, 1997, p. 102). É muito provável que muitos de nós nunca perguntaram pela existência do nariz. Ele existe como todos os outros órgãos de nosso corpo e talvez sua função mais específica seja a de proporcionar ao corpo o sentido do olfato.

Em uma relação de causa e efeito Leibniz teria afirmado que o nariz existe para sustentar os óculos. "Tal explicação confesso que até certo tempo me pareceu definitiva; mais veio um dia, em que, estando a ruminar esse e outros pontos obscuros de filosofia, atinei com a única, verdadeira e definitiva explicação" (ASSIS, 1997, p. 102). Mas, a conclusão que Cubas apresenta para a questão força necessariamente outra análise, pois não é tão simples como na descrição feita. “A conclusão, portanto, é que há duas forças capitais: o amor, que multiplica a espécie, o nariz que a subordina ao indivíduo. Procriação, equilíbrio" (Assis, 1997, p. 103). 
Nesta passagem vem à tona a questão da transcendência. A pessoa é capaz de transcender-se por ter um eixo condutor, isto é, o nariz. Ele assume aqui a função de balizas, conduz o "olhar da alma" como diz Platão, a contemplação profunda. Cubas evoca o faquir, que para enxergar a luz celeste esquece do mundo a sua volta e se perde na imensidão do universo olhando para a ponta do nariz. O exemplo usado, embora com enfoque na espiritualidade hinduísta, também transcende a essa realidade e passa para o pólo da racionalidade. O equilíbrio só será possível se o ser humano adaptar-se ao meio. O chapeleiro que não adaptou foi a falência vendo seu concorrente ir à prosperidade.

Brás Cubas vive um romance secreto com Virgília. Porém o drama existencial é tratado como que uma espécie de destino.

\begin{abstract}
Pobre destino! Onde andarás agora, grande procurador dos negócios humanos? Talvez esteja a criar pele nova, outra cara, outras maneiras, outro nome, e não é impossível que... já me não lembra onde estava... Ah! Nas estradas escuras. Disse eu comigo que já agora seria o que Deus quisesse. Era a nossa sorte amar-nos; se assim não fora, como explicaríamos a valsa e o resto? Virgília pensava a mesma coisa. Um dia, depois de me confessar que tinha momentos de remorsos, é porque me não tinha amor, Virgília cingiu-me com os seus magníficos braços, murmurando: amo-te, é a vontade do céu (Assis, 1997, p. 113).
\end{abstract}

Um pouco mais adiante ele afirma: "e estas palavras não vinham à toa. Virgília era um pouco religiosa. Não ouvia missa aos domingos, é verdade, e creio até que só ia às igrejas em dia de festa e quando havia lugar vago em algum tribunal. Mas rezava todas as noites com fervor, ou, pelo menos, com sono". (ASSIS, 1997, p. 113). A traição certamente os deixavam em situação um tanto quanto desconfortável, sobretudo para Cubas. "Lobo Neves, a princípio, metia-me grandes sustos. Pura ilusão. Como adorasse a mulher, não se vexava de me dizer muitas vezes. Achava que Virgília era a perfeição mesma, um conjunto de qualidades sólidas e finas, amável, elegante, austera, um modelo." (ASSIS, 1997, p. 114). Lobo Neves tinha na pessoa de Cubas um amigo, por isso chega a confidenciar-lhes sentimentos íntimos:

Um dia confessou-me que trazia uma triste carcoma na existência. Faltava-lhe a glória pública. Animei-o; disse-lhe muitas coisas bonitas, que ele ouviu com aquela unção religiosa de um desejo que não quer acabar de morrer; então compreendi que a ambição dele andava cansada de bater as asas, sem poder abrir vôo. Dias depois disse-me todos os seus tédios e desfalecimentos, as 
amarguras engolidas, as raivas sopitadas; contou-me que a vida política era um tecido de invejas, despeitos, intrigas, perfídias, interesses, vaidades. Evidentemente havia aí uma crise de melancolia; tratei de combatê-la (ASSIS, 1997, p. 114).

O reaparecimento de Quincas Borba se dá em situação de mendicância. Há tempos os dois amigos não se encontravam, mas o reencontro não foi tão agradável. "Não havia nele a resignação crista, nem a conformidade filosófica" (ASSIS 1997, p. 117). Borba insiste em explicar a Cubas a filosofia do Humanitismo, mas este não interessa muito nem um pouco pelo assunto mesmo diante da insistência do amigo. "Não vá sem eu lhe ensinar a minha filosofia da miséria, disse ele, escarranchando-se diante de mim" (ASSIS, 1997, p. 118). Mas depois de distanciar-se de seu velho amigo ele afirma: "quisera ver-lhe a miséria digna. Contudo, não pude deixar de comparar outra vez o homem de agora com o de outrora, entristecer-me e encarar o abismo que separa as esperanças de um tempo de realidade de outro tempo" (ASSIS, 1997, p. 119). Certamente Brás recorda dos tempos da infância, da escola, período em que seu amigo era pessoa de destaque na expressão: 'homem de outrora'.

\section{CONSIDERAÇÕES}

Uma leitura acurada em Memórias Póstumas de Brás Cubas aponta para a conclusão de que Machado de Assis deve ter lido as obras de Leibniz e Voltaire. Uma vez que, em algumas passagens do texto, ele deixa claro que conhecia os escritos dos outros dois autores filósofos, fazendo referências a Pangloss e a Cândido. Pangloss é uma personagem que Voltaire cria para ridicularizar Leibniz com sua obra $O$ Discurso $d a$ Metafísica, neste texto Leibniz apresenta este mundo como o melhor dos mundos possíveis porque é produto do humano. Voltaire, em $O$ Cândido, apresenta Pangloss como o preceptor de Cândido, dando lhes ensinamentos de metafísica e orientando que a vida é drástica, porém, é deve ser encarada como a melhor das possibilidades da existência humana. Cândido vive os piores dessabores da vida, mas está sempre convicto de que este é o melhor dos mundos possíveis.

Neste primeiro ensaio tratamos do drama existencial apresentado na obra por Machado de Assis, que coloca Brás Cubas frente a frente com situações complexas da 
humanidade. $\mathrm{O}$ autor leva seu personagem a viver na pele, assim como Cândido a problemática da existência da humanidade.

Em outra abordagem pretendemos tratar mais especificamente da teoria filosófica de Quincas Borba, ou seja o Humanitismo. Lá almejamos aprofundar nesta teoria e ver como o pretenso filósofo Borba também vive o existencialismo humano, indo da nobreza à miséria e a demência.

\section{REFERÊNCIAS}

ABBAGNANO, Nicola. Dicionário de Filosofia. Trad. Ivone C. Benedetti. São Paulo: Martins Fontes, 2000.

ASSIS, Machado de. Memórias Póstumas de Brás Cubas. São Paulo: Klick, 1997.

LEIBENIZ, Gottfreed Wilhelm. Discurso de metafísica. Trad. Marilena de S. Chauí. São Paulo: Abril Cultural, 1979.

MARTINS, Joaquim B. Da Literatura à Filosofia: 80 textos com comentários. São Paulo: Fesan, 1984.

NUNES, Benedito. Passagem para o poético: Filosofia e Poesia em Heidegger. São Paulo: Ática, 1992.

VOLTAIRE. Cândido ou otimismo. Trad. Annie Cambé. Roma, Itália: Newton Compton Editoris, 1994.

RIOS, Terezinha A. Compreender e Ensinar: por uma docência da melhor qualidade. 4. ed. São Paulo: Cortez, 2003.

REALE, Giovanni e ANTESERI, Dario. História da filosofia: do Humanismo a Kant. Vol. II. São Paulo: Paulus, 1990.

\section{Recebido em: 01/12/2021}

Aprovado em: 23/12/2021

Publicado em: 28/12/2021 